Running head: BYSTANDERS AND BIAS-BASED BULLYING

Bystander responses to bias-based bullying in schools: A developmental intergroup approach

Sally B. Palmer

UCL Institute of Education

\& Nicola Abbott

Canterbury Christ Church University

Note. Correspondence should be directed to Sally B. Palmer (s.palmer@ucl.ac.uk), Department of Psychology and Human Development, UCL Institute of Education, WC1 OAH. 
BYSTANDERS AND BIAS-BASED BULLYING 2

\begin{abstract}
Research on bystander responses to bullying shows the valuable contribution that prosocial or "defender" bystander behaviours can have in reducing bullying in schools. We propose that a developmental intergroup approach (i.e., children's developing understanding of social identities and related intergroup processes) is required to fully understand when and why children and adolescents do or do not help bullied peers in diverse contexts. We first review well-established theory and evidence from intergroup social exclusion literature to demonstrate the strength of a developmental intergroup approach when understanding responses to complex social scenarios across childhood and into adolescence. We then review recent evidence that demonstrates the importance of examining group membership, group identity and group norms to understand children and adolescents' bystander responses in bias-based bullying contexts. Finally, we consider implications for school-based interventions and next steps for research on bystander responses in childhood and adolescence.
\end{abstract}


BYSTANDERS AND BIAS-BASED BULLYING 3

\section{Bystander responses to bias-based bullying in schools: A developmental intergroup approach}

The role of peer bystanders (i.e., students who witness bullying) is a key focus of antibullying programmes (e.g., 1) as it is recognised that peers are present during the majority of bullying incidents (2). Bystanders can support the bully or ignore the act (thus reinforcing the acceptability of bullying), challenge the bully, report the incident to a teacher, garner support from friends or comfort and support the victim in other ways (e.g., 3, 4). When bystanders challenge bullying, they can reduce it and reinforce a school anti-bullying ethos $(1,5-8)$; however, defending becomes less likely with age (9).

To date, research has identified many important predictors for defending behaviours. Confidence, self-efficacy, popularity and empathy all predict helpful responses $(2,3)$. Antibullying programmes have been shaped around these findings, and meta-analyses show the benefits of programmes which support bystanders to challenge and intervene during bullying incidents $(10,11)$. The KiVa programme, which focusses on developing the socio-emotional skills of students and provides training in bystander responses, has repeatedly shown reductions in bullying across schools in Finland (e.g., 3, 4). However, research also suggests these programmes are less effective in diverse communities (6). We propose that additional influences need to be considered in the context of bias-based bullying.

We firstly review bias-based bullying and how it is distinctive to interpersonal forms of bullying. Secondly, we describe a developmental intergroup approach to understanding children and adolescents' attitudes and behaviours. We then present evidence for this approach in the context of bystander responses to bias-based bullying, focussing specifically on intergroup membership and identification, intergroup norms, loyalty and repercussions, and social-moral reasoning. Finally, we consider the implications for anti-bullying programs. 


\section{Bias-based bullying}

Bias-based bullying describes an intergroup context (i.e., involving ingroup and outgroup members) where someone is bullied due to their group membership such as their race or ethnicity, nationality, religion, gender, sexual orientation or disability (12-14). Typically, bias-based bullying is perpetrated by a member of a majority-status social group towards a member of a minority-status social group (i.e., White bully, Black victim) and constitutes discrimination. This form of bullying is rife across childhood and adolescence and has stronger negative outcomes for the victim compared to interpersonal bullying (14-17).

Increasingly bias-based bullying has been recognised as distinctive to interpersonal bullying precisely because bias-based bullying indicates underlying issues of prejudice and discrimination $(15,16,18)$. Therefore, bystander responses to bias-based bullying are likely affected by intergroup concerns. In line with this interpretation, a recent systematic review showed that anti-bullying programmes were more effective in homogenous populations compared to more diverse samples (6). This is problematic as children in diverse settings are more at risk of bias-based bullying. As such, intergroup processes (i.e., group identity, group membership, group norms, social-moral reasoning) and the developmental understanding of these processes are likely to inform children and adolescents' responses to bias-based bullying (see also 13).

\section{Developmental Intergroup Approach}

Research examining the development of children's attitudes towards, and evaluations of, intergroup social exclusion, aggression and helping (e.g., 15, 19-21) consistently shows the importance of intergroup processes when interpreting children and adolescents changing attitudes and behaviours towards members of different groups. This developmental intergroup approach (e.g., 19, 22, 23) shows how intergroup processes shape the way in 
which children and adolescents reason about, and respond to, social situations. Moreover, they influence how attitudes and behaviours develop across childhood and adolescence because of changing social-cognitions and experience of intergroup contexts $(19,24,25)$.

From early on children become aware of social categories and affiliate with those they see as similar (ingroup) and differentiate themselves from those they view as different (outgroup) (26). At this stage, ingroup preference guides attitudes and behaviours during intergroup contexts. From middle childhood, as perspective-taking skills develop, evaluations of others are also based on whether their behaviour conforms with, or deviates from, group norms such as loyalty $(22,27)$.

Children also recognise that challenging ingroup norms can result in negative evaluations and other social repercussions. With increased experience of groups, what might be perceived as morally wrong in early and middle childhood (i.e., it's never OK to exclude another person) can be viewed as relatively more acceptable from later childhood into adolescence (i.e., it's OK to exclude Sarah from soccer practice because she's a girl and probably isn't any good at soccer). Thus, negative social interactions can be justified through perceived knowledge of groups and group expectations $(19 ; 22)$.

Together with social experience, developing social cognitions (i.e., perspective taking, understanding group norms, group loyalty and group-related repercussions) influence evaluations and social-moral reasoning about social incidents such as social exclusion and aggression $(22,24,25)$. We propose these same group processes influence when children and adolescent bystanders do, or do not, help victims of bias-based bullying. Due to the developmental nature of such processes, we propose they can also help explain the developmental decline in defending responses.

\section{Bystanders and a Developmental Intergroup Approach}


BYSTANDERS AND BIAS-BASED BULLYING 6

Intergroup membership and identification. Initial research demonstrates that children and adolescent bystander responses are influenced by intergroup processes $(9,28$ 30). Nesdale, Killen and Duffy (31) showed that, when an act of aggression was perpetrated by an ingroup member towards an outgroup member, sharing the same group membership as the aggressor (as opposed to being unaffiliated with the group) resulted in less negative attitudes towards the perpetrator.

Extending these findings, Palmer et al. (9) examined children and adolescent bystander responses to bias-based verbal bullying, showing that, with age, helping intentions were higher when the victim was an ingroup member compared to when they were an outgroup member. This finding was mediated by increased social identification; a bystander could not simply view themselves as belonging to the same category, they also had to find meaning in that social category. This research not only highlighted the importance of intergroup processes for bystander intentions, but demonstrated how these processes become increasingly influential with age, as social cognition and importance of identity increases (24, 25).

Further demonstrating the importance of group membership for bystander responses, a recent study with adolescent bystanders showed that stronger ingroup bias (preference for one's own group) was negatively related to helping a bullied immigrant (outgroup) peer (28). Consequently, when examining bystander responses, the relative ingroup-outgroup affiliations between all parties could indicate when helping is most or least likely. On this premise, a bystander who identifies with the bully would be more likely to support (less likely to challenge) the bully (31). If the bystander identifies with the victim, they would be more likely to offer help (see Figure 1a and 1b).

(Insert Figure $1 \mathrm{a}$ and $1 \mathrm{~b}$ here) 
Intergroup norms, loyalty, and repercussions. The developmental intergroup approach extends beyond the relative group memberships of those involved. Research on social exclusion shows the strength of group-norms on children's evaluations of peers over and above group membership $(19,27)$. In the intergroup context, group-norms refer to the expectations affiliated with one group that are different to those affiliated with expectations of another. In this way, they are different to classroom norms (i.e., an anti-bullying ethos) that have also been shown to be predictive of defender responses to interpersonal bullying (e.g., 2, $7,8)$.

Children increasingly focus on group-specific norms when forming evaluations of others, in part due to the development of cognitive perspective-taking abilities (e.g., 24, 27) and increasing social experience (e.g., 25, 32). With age, relative group norms have a stronger influence on ingroup and outgroup evaluations. For example, children will endorse ingroup aggression when doing so fits with an ingroup norm (33). Furthermore, endorsing bias-based acts (i.e., telling a racist joke) is more likely when a specific-group norm for doing so is present (19).

Evaluations of ingroup members who challenge ingroup norms (“deviants" or “dissenters") become increasingly negative with age, and evaluations of outgroup members who behave in line with ingroup norms become more positive (27). This happens even in the context of negative group norms, such as endorsing race-based jokes (29). Mulvey et al. showed, across adolescence, participants become increasingly concerned about group-based repercussions for bystanders who challenge a group norm for telling race-based jokes, expecting it to result in exclusion from the peer group. Consequently, an increasing knowledge of group dynamics can reduce the likelihood of bystander defending. 
Additionally, research shows that children will evaluate members of an outgroup with an exclusive norm (not liking and excluding other members) more negatively, whereas those with an inclusive group norm (liking and including other group members) will be viewed more positively (32). Consequently, bystander responses to bias-based bullying likely depend on group-specific norms (actual or perceived). For example, if a British child was a bystander to a bullying incident where another British child bullied an immigrant child, and the British group holds an inclusive norm, this should increase the likelihood of helping the outgroup member (as the ingroup bully is dissenting from the group inclusion norm) compared to when the British group holds an exclusive group norm (see Figure $2 \mathrm{a}$ and $2 \mathrm{~b}$ ). If the British group holds an exclusive ingroup norm, ingroup bystanders should demonstrate support for their own group, resulting in reduced outgroup helping.

Extending this logic, when bystanders perceive outgroups as "exclusive", victimised members of these exclusive outgroups may be seen as less in need, or less wanting or deserving of help (e.g., 34). This would result in reductions in helping. Importantly, perceptions of - and stereotypes about - victimised groups may drive bystander responses regardless of the bystander's own affiliations (i.e., as a member of the perpetrator's group or of an unrelated third party).

(Insert Figure $2 \mathrm{a}$ and $2 \mathrm{~b}$ here)

Generic norms (i.e., expectations held by society generally) are also important for defender behaviour, with research in both interpersonal and intergroup contexts providing support for their influence (e.g., 7-9). Behaving in line with societal or broader group-level norms can mediate the developmental decline in prosocial bystander intentions to bias-based bullying; for example, older children who perceive a norm for helping among their peergroup are more likely to help than those who do not (9). Developmental intergroup research 
suggests that broader generic norms interact with group-specific norms during intergroup contexts (32). More research is required in order to determine when generic-level norms may override group-specific norms in the bystander context, and how this effect may differ across childhood and into adolescence.

Social-moral reasoning. Children and adolescents' reasoning about responses to bias-based bullying further demonstrates the social-cognitive processes underpinning bystander responses. With age, children become more adept at weighing up competing concerns in response to social scenarios (e.g., 15, 19, 24). Although bias-based bullying is overwhelmingly viewed as unacceptable and can always be considered a moral issue (i.e., someone is being harmed, injustice and inequality are present); as children get older they become increasingly aware of additional group-related concerns (i.e., norms, repercussions) and sometimes these are prioritised over their moral judgments of transgressions (e.g., 19, 22).

Younger children typically justify negative evaluations of social exclusion by focussing on the morality of a situation (i.e., it is unacceptable because it is unfair, wrong, causing harm to someone). With age, the moral component is still acknowledged, but children become more cognitively able to weigh moral concerns against competing concerns, such as "social-conventional" issues (i.e., is there a rule or group norm that suggests this behaviour is [un]acceptable?) or "psychological" issues (i.e., is this my responsibility, is there anything I can do about this, do I want to help, is it that big of a deal?).

When asking participants to reason about their bystander responses, Palmer et al. (9) showed that younger children, who also reported helping intentions more often than adolescents, presented moral justifications more frequently. Adolescents were slightly more likely to draw on social-conventional concerns, and significantly more likely to draw on 
psychological concerns when reasoning about their decision to help. Mulvey et al. (29) demonstrated that older adolescents were more likely to "play down" the negative nature of a bias-based act compared to younger adolescents. This was also related to perceiving the act as relatively more acceptable. Social-moral reasoning thus sheds further light on the way in which social experience and group processes play a role in young people's bystander choices, and are particularly important when considering the age-related trends in bystander defending $(6,11)$.

\section{Implications for anti-bullying interventions}

Anti-bullying programs that focus on promoting helpful bystander intervention make an important contribution to reducing bullying in schools (1). However, considering the lack of focus on bias-based bullying within anti-bullying interventions, it is perhaps unsurprising that anti-bullying techniques are less effective in heterogeneous populations $(6,15)$.

Typically, schools have taken a reactive and bully-victim approach when tackling all forms of bullying, a "one size fits all" method. This can be particularly difficult for practitioners when dealing with bias-based bullying, often accompanied by controversial and contentious issues such as xenophobia and immigration, as it relies on practitioners only dealing with these issues after a negative act has been perpetrated.

We propose that promoting more inclusive attitudes towards a range of social groups may be more useful, as practitioners can then refer students back to these discussions when dealing with specific incidents of bias-based bullying. Indeed, evidence from the developmental intergroup approach suggests that taking a more proactive approach to antibullying interventions, one that taps into wider intergroup phenomenon (i.e., fostering overarching identities while valuing difference and creating inclusive norms), might be a more constructive route to encouraging prosocial bystander responses to bias-based bullying. 
To facilitate these aims, interventions could also draw from recent research in the intergroup field. For example, intergroup contact interventions (encouraging positive interactions with members of outgroups) have been shown to improve attitudes, intentions and behaviours towards outgroup members $(35,36)$. Recently, research has shown how cross-group friendships and other forms of intergroup contact are positively related to bystander helping (28) and negatively related to passive bystander responses (30). Thus, improving attitudes towards others by embedding contact interventions into anti-bullying programmes is one way in which practitioners could improve prosocial and defender responses to bias-based bullying.

\section{Conclusion}

This review aimed to highlight the importance of the developmental intergroup context when examining bystander responses to biased-based bullying. Grounded in the wellestablished theoretical and empirical work on social exclusion, we hope researchers will be inspired to utilise predictions of, and existing support for, a developmental intergroup approach into the study of when and why children and adolescents defend victims of biasedbased bullying. The evidence presented here shows that group processes are important predictors of bystander responses during bias-based bullying contexts. It is likely that these processes interact with individual differences such as empathy and openness (28), and this remains to be explored in future research.

The intergroup concepts reviewed here are the tip of the iceberg. Developmental intergroup theories also relate concepts of intergroup status (i.e., 37, 38) and intergroup threat (i.e., 15,39$)$ to children's evaluations of intergroup scenarios. These remain to be explored in the context of defending intentions and behaviours. We believe that examining bystander responses from a developmental intergroup perspective will inform the development and 
implementation of more appropriate anti-bullying interventions in diverse settings (6) that will more effectively target and tackle bias-based bullying in schools. 


\section{References}

1. Polanin, J., Espelage, D.L., \& Pigott, T.D. (2012). A meta-analysis of school-based bullying prevention programs' effects on bystander intervention behaviour. School Psychology Review, 41, 47-65.

2. Salmivalli, C. (2014). Participant roles in bullying: How can peer bystanders be utilized in interventions? Theory Into Practice, 53, 286-292. doi:10.1080/00405841.2014.947222

3. Saarento, S., \& Salmivalli, C. (2015). The role of classroom peer ecology and bystanders' responses in bullying. Child Development Perspectives, 9, 201-205. doi: $10.1111 /$ cdep. 12140

4. Karna, A., Voeten, M., Little, T.D., Poskiparta, E., Kaljonen, A. \& Salmivalli, C. (2011). A large-scale evaluation of the KiVa antibullying program: Grades 4-6. Child Development, 82, 311-330. doi:10.1111/j.1467-8624.2010.01557.x

5. Aboud, F., \& Joong, A. (2008). Intergroup name-calling and conditions for creating assertive bystanders. In S.R. Levy \& M. Killen (Eds.), Intergroup attitudes and relations in childhood through adulthood (pp. 249-260). New York, NY: Oxford University Press.

6. Evans, C.B.R., Fraser, M.W., \& Cotter, K.L. (2014). The effectiveness of schoolbased bullying prevention programs: A systematic review. Aggression and Violent Behavior, 19, 532-544. doi:10.1016/j.avb.2017.07.004

7. Salmivalli, C., Voeten, M., \& Poskiparta, E. (2011). Bystanders matter: Associations between reinforcing, defending, and the frequency of bullying behavior in classrooms. Journal of Clinical Child and Adolescent Psychology, 40, 668-676. doi:10.1080/15374416.2011.597090 
8. Salmivalli, C., \& Voeten, M. (2004). Connections between attitudes, group norms, and behavior in bullying situations. International Journal of Behavioral Development, 28, 246-258. doi:10.1080/01650250344000488

9. Palmer, S.B. Rutland, A. \& Cameron, L. (2015). The development of bystander intentions in an intergroup context: The role of perceived severity, ingroup norms, and social-moral reasoning. British Journal of Developmental Psychology, 33 (4), 419433. doi:10.1111/bjdp.12092

10. Merrell, K.W., Gueldner, B.A. Ross, S.W., \& Isava, D.M. (2008). How effective are school bullying intervention programs? A meta-analysis of intervention research. School Psychology Quarterly, 23, 26-42. doi:10.1037/1045-3830.23.1.26

11. Ttofi, M.M., \& Farrington, D.P. (2011). Effectiveness of school-based programs to reduce bullying: A systematic and meta-analytic review. Journal of Experimental Criminology, 7, 27-56. doi:10.1007/s11292-010-9109-1

12. Juvonen, J. \& Graham, S. (2014). Bullying in schools: The power of bullies and the plight of victims. Annual Review of Psychology, 65, 159-185. doi:10.1146/annurevpsych-010213-115030

13. Mikami, A.Y., Lerner, M.D., \& Lun, J. (2010). Social context influences on children's rejection by their peers. Child Development Perspectives, 4, 123-130. doi:10.1111/j.1750-8606.2010.00130.x

14. Russell, S. T., Sinclair, K. O., Poteat, V. P., \& Koenig, B. W. (2012). Adolescent health and harassment based on discriminatory bias. American Journal of Public Health, 102, 493-495. doi:10.2105/AJPH.2011.300430

15. Killen, M., Mulvey, K.L., \& Hitti, A. (2013). Social exclusion: A developmental intergroup perspective. Child Development, 84, 772-790. doi:10.1111/cdev.12012 
16. Killen, M., Rutland, A., \& Ruck, M.D. (2011). Promoting equity, tolerance and justice in childhood. SRCD Social Policy Report, 25(4), 1-33.

17. Menesini, E. \& Salmivalli, C. (2017). Bullying in schools: The state of knowledge and effective interventions. Psychology, Health \& Medicine, 22, 240-253. doi: $\underline{10.1080 / 13548506.2017 .1279740}$

18. Formby, E. (2015). Limitations of focussing on homophobic, biphobic, and transphobic "bullying" to understand and address LGBT young people's experiences within and beyond school. Sex Education, 15, 626-640. doi:10.1080/14681811.2015.1054024

19. Mulvey, K.L. (2016). Children's reasoning about social exclusion: Balancing many factors. Child Development Perspectives, 10, 22-27. doi:_10.1111/cdep.12157

20. Rutland, A. \& Killen, M. (2017). Fair resource allocation among children and adoelscents: The role of group and developmental processes. Child Development Perspectives, 11, 56-62. doi:10.1111/cdep.12211.

21. Sierksma, J., Thijs, J., \& Verkuyten. M. (2014). Children's intergroup helping: The role of empathy and peer group norms. Journal of Experimental Child Psychology, 126, 369-383. doi: 10.1016/j.jecp.2014.06.002

22. Rutland, A. \& Killen, M. (2015). A Developmental Science Approach to Reducing Prejudice and Social Exclusion: Intergroup Processes, Social-Cognitive Development, and Moral Reasoning. Social Issues and Policy Review, 9(1), 121-154. doi:10.1111/sipr.12012

23. Rutland, A., Killen, M., \& Abrams, D. (2010). A new social-cognitive developmental perspective on prejudice: The interplay between morality and group identity. Perspectives on Psychological Science, 5, 279-291. doi:10.1177/1745691610369468 
24. Abrams, D., Rutland, A., Palmer, S. B., Pelletier, J., Ferrell, J., \& Lee, S. (2014). The role of cognitive abilities in children's inferences about social atypicality and peer exclusion and inclusion in intergroup contexts. British Journal of Developmental Psychology, 32, 233-247. doi:10.1111/bjdp.12034

25. Nesdale, D., Zimmer-Gembeck, M.J. \& Roxburgh, N. (2014). Peer group rejection in childhood: Effects of rejection ambiguity, rejection sensitivity, and social acumen. Journal of Social Issues, 70, 12-28. doi:10.1111/josi.12044

26. Nesdale, D. (2004). Social identity processes and children's ethnic prejudice. In M. Bennett \& F. Sani (Eds.), The development of the social self (pp. 219-246). New York, NY: Psychology Press.

27. Abrams, D., Powell, C., Palmer, S.B., \& Van de Vyver, J. (2017). Toward a contextualized social developmental account of children's group-based inclusion and exclusion: The developmental model of subjective group dynamics. In A. Rutland, D. Nesdale \& C. Spears Brown (Eds.), The Wiley Handbook of Group Processes in Children and Adolescents (pp. 455-471). UK: John Wiley \& Sons Ltd.

28. Abbott, N., \& Cameron, L. (2014). What makes a young assertive bystander? The effect of intergroup contact, empathy, cultural openness, and in-group bias on assertive bystander intervention intentions. Journal of Social Issues, 70,167-182. doi:10.1111/josi.12053

29. Mulvey, K.L., Palmer, S.B. \& Abrams, D. (2016). Race-based humour and peer group dynamics in adolescence: Bystander intervention and social exclusion. Child Development, 87. 1379-91. doi: 10.1111/cdev.12600.

30. Palmer, S.B., Cameron, L., Rutland, A. \& Blake, B. (2017). Majority and minorityethnic status adolescents' bystander responses to racism in schools. Journal of Community and Applied Social Psychology. doi:10.1002/casp.2313. 
31. Nesdale, D., Killen, M., \& Duffy, A. (2013). Children's social cognition about proactive aggression. Journal of Experimental Child Psychology, 116, 674-692. doi:org/10.1016/j.jecp.2013.07.003

32. Nesdale, D., \& Lawson, M. J. (2011). Social groups and children's intergroup attitudes: Can school norms moderate the effects of social group norms? Child Development, 82, 1594-1606. doi:10.1111.j.1467-8624.2011.01637.x

33. Nipedal, C., Nesdale, D. \& Killen, M. (2010). Social group norms, school norms and children's aggressive intentions. Aggressive Behavior, 36, 195-204. doi:10.1002/ab.20342

34. Sierksma, J., Thijs, J., Verkuyten, M., \& Komter, A. (2014). Children's reasoning about the refusal to help: The role of need, costs, and social perspective taking. Child Development, 85, 1134-49. doi:10.1111/cdev.12195

35. Cameron, L. \& Abbott. N. (2017). Intergroup contact in action: Using intergroup contact to change children's outgroup orientation. In A. Rutland, D. Nesdale \& C. Spears Brown (Eds.), The Wiley Handbook of Group Processes in Children and Adolescents (pp. 455-471). UK: John Wiley \& Sons Ltd.

36. Turner, R.N. \& Cameron, L. (2016). Confidence in contact: A new perspective on promoting cross-group friendship among children and adolescents. Social Issues and Policy Review, 10, 212-246. doi:10.1111/sipr.12023

37. Dunham, Y., Newheiser, A.K., Hoosain, L., Merrill, A. \& Olson, K.R. (2014). From a different vantage: Intergroup attitudes among children from low- and intermediatestatus racial groups. Social Cognition, 32, 1-21. doi:10.1521/soco.2014.32.1.1

38. Feddes, A.R., Monteiro, M.B., \& Justo, M.G. (2013). Subjective social status and intergroup attitudes among majority and minority children in Portugal. British Journal of Developmental Psychology, 32, 125-140. doi:10.1111/bjdp.12025. 
39. Nesdale, D., Maas, A., Durkin, K. \& Griffiths, J. (2005). Group norms, threat, and children's racial prejudice. Child Development, 76, 652-63. doi:10.1111/j.14678624.2005.00869.x 


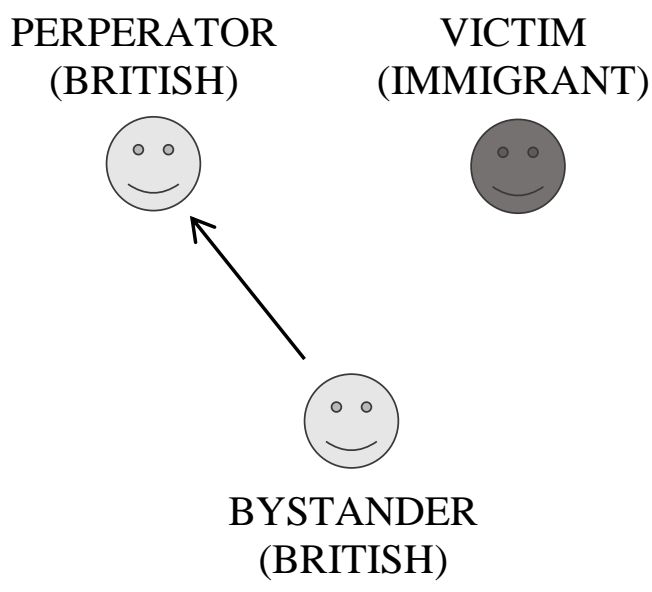

Figure 1a. Bystander shares group membership with perpetrator. Note. Arrow indicates bystander support.

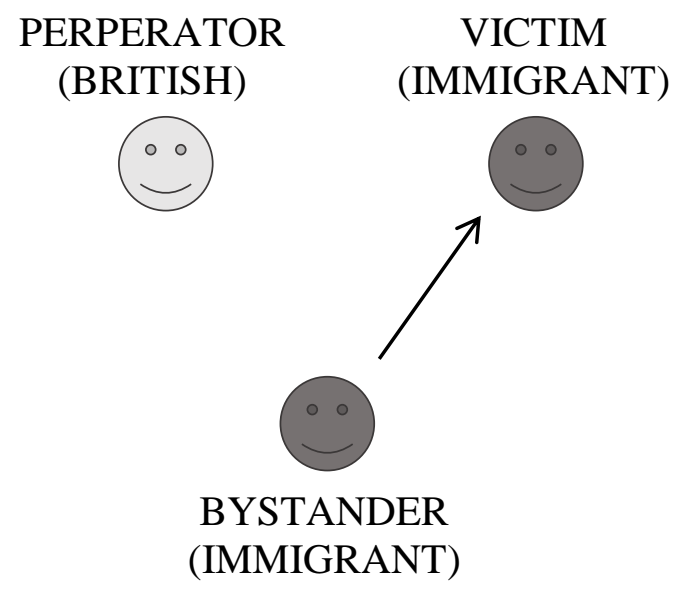

Figure 1b. Bystander shares group membership with victim. Note. Arrow indicates bystander support. 
BYSTANDERS AND BIAS-BASED BULLYING 20

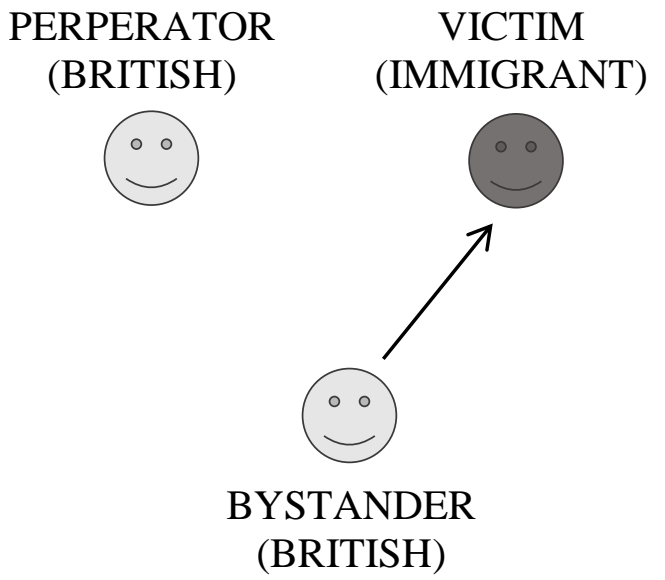

Figure 2a. Inclusive Norm. Note. Arrow indicates bystander support.

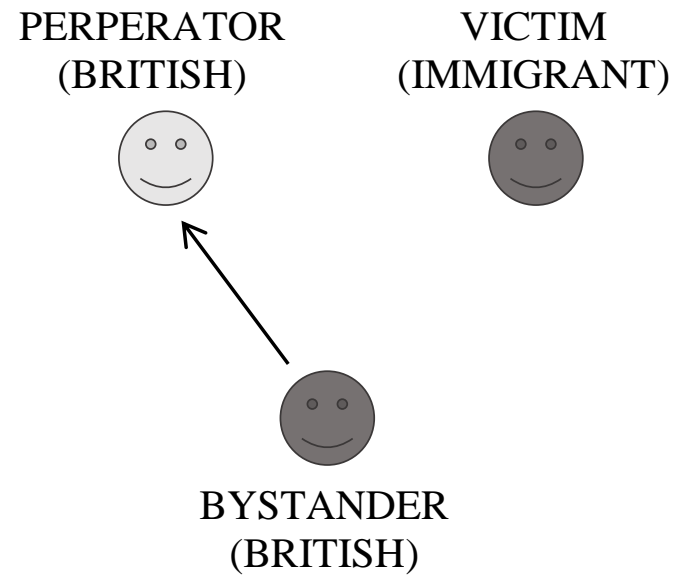

Figure 2b. Exclusive norm. Note. Arrow indicates bystander support. 